has the biquartz. Two strips of heavy-glass of exactly equal length and similar quality, such as those I hold in my hand, must be introduced in the respective paths of the two beams: and one at least of them must be surrounded by a magnetizing coil. The biquartz has wiped out the interference fringes; but on magnetizing one of the two pieces of heavy-glass, or on magnetizing the two in opposite senses, the interference bands can be made to reappear. It is in this way that Prof. Sohncke's experiment-hardly suitable for a lecture theatre-was performed. It is in this way that we establish upon an experimental basis the fact that light itself, and not merely the plane of its polarization, experiences an optical torsion when subjected to those forces which, whether crystalline, molecular, or magnetic, exert upon it an optical torque.

\section{BABYLONIAN ASTRONOMY.1}

\section{II}

THE year--that is, the period bringing back the recurrence of the seasons--is not a primitive means of dividing time, but the result of many observations. The simplest way of marking time is by seasons, and the system is still employed by some savage nations in Africa. A season does not correspond to one year, and more than one may be in a year ; seasons, however, generally correspond to the year period. As to the division of the year, it must have varied according to the climate and region, but the simplest is by ten, as ten is the most common dividing number, and such was the one originally adopted by the Semites and Egyptians. This year of ten months, or rather ten parts, has left traces among the Semites and in classical anthors. The Babylonians assimilated their first ten kings to the ten parts of the year. At Rome, we are told that the year before Numa Pompilius was composed of ten months only.

A year of ten lunar months is impossible, for after two or three of such periods it would no longer correspond with the seasons. We find, therefore, that the ten parts of the year were composed of thirty-six days distributed in four periods or weeks of nine days. This last division was not, however, official : the days of each of the ten divisions of the year were merely numbered from one to thirty-six; it was at a later date that the days received names from the protecting gods attributed to them.

It is to be noticed that in Egypt the months had no special names; the year was divided, after the reform of the calendar, into three seasons of four months of thirty days, called first, second, and so on, of the season to which they belonged. Popular names were attributed to them afterwards, taken from the religious festivals, but they do not appear in the texts before the Ptolemaic period. The like took place among the Semites: the months were called first, second, third, and so on, but were not distributed into seasons. It was only after the Akkadian invasion that the other names, Nisan, Tyyar, \&c., were adopted, and the eighth month never lost its numerical name. In the astronomical omen tablets the primitive nomenclature by numerical order was often preserved.

It is still uncertain at what time the old calendar of ten divisions of thirty-six days was reformed into one of twelve months of thirty days. The change was due to the desire to measure the time by the appearance of the moon. This reform may be due to the influence of the Akkadians, who made the conquest of Babylon about 7000 B.c. These people had a lunar calendar composed of thirteen months of twenty-eight days, giving, therefore, a year of 364 days. It was no doubt more accurate than the Semitic calendar, but the Akkadians adopted their subjects' calendar. The deficiency with the normal solar year of 365 days was made up by means of a supplementary month placed irregularly by the priests when they thought it necessary. That is why we find various intercalary months, and why, in some cases, as late even as Nebuchadnezzar the Great, they occur in three successive years. To make up the deficiency the Babylonians had also a supplementary day called the "heavy 2 Ist," which could be inserted in any month before the normal 2 rst. We find the mention of such supplementary days in several consecutive months.

The Akkadians, before invading Babylonia, divided their month into four parts or weeks of seven days each. This division had, however, nothing to do at first with the planets, to which the days were assimilated only at a later date. The Akkadians

I Abstract of the second lecture delivered by Mr. G. Bertin at the British Museum. Continued from p. 237 .

looked on the planets as evil spirits disturbing by their irregular motion the harmony of heaven ; and, as evil spirits were the chief objects of their worship, they naturally attributed to each day of the week the name of a planet. When the Akkadians adopted the Semitic month of thirty days, the wcek of seven days was naturally abandoned in common use, but it was retained for religious purposes with some modification, a new series of $f$ ur weeks commencing with each month. The Semites rejected the Akkadian names of the days of the week, though they preserved the symbolism attached to them, as is shown by the seven tablets buried under the foundation-stone of Khorsabad.

Our names of the days of the week are derived from the Akkadian assimilation of these days to the planets. There is no doubt as to the order in which the planets were assimilated to the names of the days, if we compare them with the colours of the walls of Ekbatana built by a Medic tribe, which preserved the primitive religion of the Akkadians, and also with the tablets of Khorsabad. The following table will show the correspondence :-

$$
\begin{aligned}
& \text { Names of the days and } \\
& \text { planets. }
\end{aligned}
$$

I Sunday (the Sun)...

2 Monday (the Moon)

3 Tuesday (Mars) ...

4 Wednesday (Mercury)

5 Thursday (Jupiter)

6 Friday (Venus) ...

7 Saturday (Saturn)...

Iron, corresponding to Thursday, or Jupiter, is represented by a red colour, no doubt on account of the rust, which is red. And we must not be surprised to see Venus represented symbolically by black, for Vesper or the Evening Star is really the dusky.

This proves that the week of seven days, which is found all over Asia and Europe, spread, not from Babylonia, but from the country whence came the Akkadians.

\section{THE INSTITUTION OF MECHANICAL ENGINEERS.}

THE summer meeting of this Institution was held in Paris last week under the presidency of Mr. Charles Cochrane.

The papers offered for reading and discussion were a description of the lifts in the Eiffel Tower, by Mr. A. Ansaloni, of Paris, supplemented by the results of working to date, communicated verbally by Mr. Gustave Eiffel, President of the Sociéte des Ingénieurs Civils; the rationalization of Regnault's experiments on steam, by Mr. J. Macfarlane Gray ; on warp-weaving and knitting without weft, by Mr. Arthur Paget ; on gas-engines, with description of the Simplex engine, by Mr. E. Delamare Deboutteville; on the compounding of locomotives burning petroleum refuse in Russia, by Mr. T. Urquhart ; and description of a machine for making paper bags, by Mr. Job Duerden.

In the discussion of the first paper, which, as its title shows, was mainly technical in character, the interesting meteorological circumstance of the Eiffel Tower acting as a thunder-cloud discharger was referred to; clouds laden with electricity having passed quietly over the region of the tower, which previously and afterwards flashed with lightning. It was also pointed out that the perpendicularity of the building is not affected by temperature variations, nor by any wind pressur e hitherto recorded.

We have not received a copy of the paper by Mr. Gray, who reserves the right of reproducing it, but from the syllabus of papers published by the Institution of Mechanical Engineers, it may be stated that Mr. Gray proposes a new unit of heat, which he compares with the ordinary water-unit, and a new diagram of energy, which he calls the Theta-phi $(\theta \phi)$ or temper. ature-entropy diagram, a graphic representation of the CarnotClausius fundamental principle, of which the area shows heatunits, the co-ordinates being the temperature, $\theta$, and entropy, $\phi$. He compares Regnault's experimental steam-pressures with the pressures calculated by means of his formulæ, showing closer agreement than is obtained by Regnault's most accurate formulæ.

In Mr. Paget's paper the three chief methods of making fabric or cloth or tissue from yarns or threads, viz. ordinary weaving, knitting, and what the author calls warp-weaving, are referred to. The paper describes the method by which shaped goods can be made by warp-weaving, and the machine by which this is effected. The machine, which is of a very ingenious character, 
comprising several interesting points of construction and detail, is at work at the Paris Exhibition.

Mr. Deboutteville, in his paper, first reviews the gas-engines hitherto proposed or employed. He carrie; back his researches nearly a century, when the first gas-engine was proposed by Barber, and completes them with a description of the Simplex engine, which he brought out with $\mathrm{Mr}$. Malandin in 1884 . This engine is founded on principles laid down by Mr. Beau de Rochas-that, to realize the best results from the elastic force of gas, the cylinders should have the greatest capacity with the smallest circumferential surface, the speed should be as high as possible, the cut-off should be as early and the initial pressure as high a; possible. In the author's engine the ignition is effected by a practically continuous electrical spark; the air and gas are mixed in an external receptacle fixed on the cover of the slide, and are drawn in through channels of varied forms so as intimately to mix them. The governors described act on the principle of totally cutting off the supply of gas for one or more strokes whenever an increase of speed occurs. From the tests made with this engine the consumption of gas is low, and it appears to compare favourably with good steam-engines as regards economy of application.

Besides the reading and discussion of papers, the members of the Institution visited the Exhibition, and various works which were opened for this purpose.

\section{SCIENTIFIC SERIALS.}

Trie numbers of the Fournal of Botany for June and July are chiefly devoted to articles interesting to students of systematic or geographical botany, especially that of our own islands; the latter number contains a biographical sketch of the late Prof. Reichenbach, by the editor.

THE most interesting article in the Botanical Gazetle for May is the commencement of a detailed paper by $\mathrm{Mr}$. C. Robertion, on the relations between insects and flowers in regard to A merican plants. The number for June contains original articles by $\mathrm{Mr}$. II. L. Bolley, on sub-epidermal rusts, and by Mr.J. N. Rose, on the Achenia of Coreopsis.

THE American Meleorological Journal for May contains abstracts of the papers read at the meeting of the New England Meteorological Society on April I6:-In a paper on lightning and the electricity of the atmosphere, Mr. McAdie gave an account of some kite experiments at the Blue Hill Observatory, near Boston, in which the potential was determined at various heights. He also referred to the observations on the character of lightning at the top of Mount Washington during thunderstorms, and to the effect of the electrification of the air upon water, dust, and other particles in it, and to the possibility of foretelling the moment of a flash of lightning.-Prof. W. M. Davis made a report upon the investigation of the sea-breeze, undertaken in 1887 , from observations at 100 stations. One fact shown was that the diurnal range of temperature, which is riminished on the coast by the action of the sza-breeze, is not lessened at the inland stations, - Mr. E. B. Weston read a paper on the practical value of self-recording rain-gauges, referring to the importance of knowing the hourly falls when constructing drainage systems.--Prof. H. A. Hazen continues the discussion upon anemometer conparisons, and upon the question of the probable effect of the monentum of heavy cups, when placed on a whirling machine. He considers that the Robinson anemometer is by far the best instrument ever devised for variable winds. - Lieut. Finley discusses the frequency of tornadoes in Illinois for fifty-four years, ending with I888. The total number of storms was I4I. The month of greatest frequency was May, no month being free from storms. The prevailing direction of movement was north-east. - Prof. Harrington communicates the instructions issued by the Chief Signal Officer for the preparation of forecasts and for their verification. The instructions contain nearly 200 regulations, and are very interesting to those who study weather predictions.

THE Meteorologische Zeitschrift (Vienna) for June contains the first part of an epitome of Dr. von Bezold's papers on the thermo. dynamics of the atmosphere, which have already been summarized in our notices of Societies. -Dr. J. Hann contributes a valuable article on the results of the meteorological observations of the late Prof. A. Ackermann at Port-au-Prince, Hayti, I8;4-68, being a part of the world where they are of special value. The observations were rescued from entire loss by the exertions of Dr. IJann and Prof. J. Scherer, the originals having been wilfully destroyed. The distribution of rainfall is much affected by the mountain features of the island; in the north the rainy season is from December to April, while in the south it is from May to July. The average yearly rainfall at Port-au-Prince, from the above observations, was $6 \mathrm{I}$ inches, on 153 days. The greatest daily fall was $5^{\circ} 6$ inches in May I 865 , the rain lasting four hours. The climate is very equable; the mean of the absolute maximum temperatures was $98^{\circ} \cdot 2$, and of the minimum $56^{\circ} \cdot 8$. - Dr. von Lepel describes his experiments in passing electric sparks through gla is tubes lined with a thin coating of paraffin, and containing a small amount of moisture, and points out that during thunderstorms many similar discharges may be observed, and may find their explanation in these experiments. The sparks differ in character and in colour, and the author argues that the humidity in the tube may be compared to the particles of vapour in the thunder-clouds, and that the coating of paraffin may have the same optical effect as the translucent clouds themselves. He gives the results of his thunderstorm observations on these lines during the summer of the year 1888 .

\section{SOCIETIES AND ACADEMIES}

LONDON.

Physical Society, June 22.--Prof. Reinold, F.R.S. President, in the chair.-The following communications were made:- Note on some photographs of lightning, and of "black" electric sparks, by Mr. A. W. Clayden. The lightning photographs, three in number, were obtained during the storim on June 6 . Two flashes, seen on one plate, show complicated and beautiful structure: one of them is a multiple flash, and flame-like appendages point upwards from every angle; the other is a broad ribbon, and, although the plate shows signs of movement, the displacement is not in a direction such as would produce a ribbon-like effect from a linear flash. The second plate shows four flashes, none of which are ribbon-like, though the camera had moved considerably. The third plate was exposed to six flashes, one of which was believed to pass down the middle of the plate ; but, on development, only a triple flash in one corncr of the plate was seen. Careful search, however, revealed the central flash as a dark one with a white core, and other dark flashes were subsequently found. The plate was very much over-exposed, and this suggested that black flashes might be due to a sort of cumulative action caused by the superposition of the glare from a white cloud upon the normal image of the flash. To test this, sparks from a Wimshurst machine were photographed, and, before development, the plates were exposed to diffused gas-light for a short time. The bright sparks yielded normal images with reversed margins, and the faint ones were completely reversed. Other experiments showed the reversal to spread inwards as the time of exposurc to gas-light increased. Finally, reversal was effected by placing a white screen behind the spark, to represent a white cloud, the only illamination being that of the spark itself. In the discussion which followed, Mr. W. N. Shaw exhibited a photograph taken during the same storm, which is particularly rich in dark flashes branching outwards from an intensely bright one. In some places the bright line has dark edges, and in one part a thin bright line runs along the middle of an otherwise dark portion of the flash. In answer to Mr. Inwards, Mr. Shaw said the plate was exposed about half a minute, and the former thought that, under those conditions, the appearance of the plate did not contradict Mr. Clayden's hypothesis. Speaking of the same photograph, Prof. Perry considered that Mr. Clayden's observations would explain the result, for a bright flash required more exposure to diffused light to reverse it than a faint one did. Prof. Ramsay reminded the meeting that Prof. Stokes's "oxides of nitrogen" explanation was still a possible one; and Mr. C. V. Burton asked whether they may be due to faint sparis cutting off light from brightly illuminated clouds, just as a gas-flame absorbs light from a brighter source. In reply, Mr. Clayden thought the "oxides of nitrogen" hypothesis improbable, and said his experiments did not enable him to answer Mr. Burton's question. As regards Mr. Shaw's plate, he believed the diffused light from the clouds would be su ficient to reverse the fainter tributary flashes, although it was insufficient to reverse the primary one. From data obtained when the ribbon-flash was taken, he had made some calculations which gave the height of the clouds about Iooo yards, and the ribbon-flash 1300 yards 